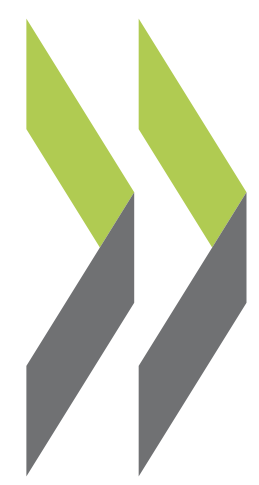

OECD Regional Development Working Papers 2013/09

The Role of Incentives in Co-operation Failures

David Bartolini 


\section{OECD REGIONAL DEVELOPMENT WORKING PAPERS}

This series is designed to make available to a wider readership selected studies on regional development issues prepared for use within the OECD. Authorship is usually collective, but principal authors are named. The papers are generally available only in their original language English or French with a summary in the other if available.

The opinions expressed in these papers are the sole responsibility of the author(s) and do not necessarily reflect those of the OECD or the governments of its member countries.

Comment on the series is welcome, and should be sent to either gov.contact@oecd.org or the Public Governance and Territorial Development Directorate, 2, rue André Pascal, 75775 PARIS CEDEX 16, France.

OECD Regional Development Working Papers are published on http://www.oecd.org/gov/regional/workingpapers

Applications for permission to reproduce or translate all or part of this material should be made to: OECD Publishing, rights@oecd.org or by fax 33145249930.

(C) OECD 2013 


\title{
THE ROLE OF INCENTIVES IN CO-OPERATION FAILURES*
}

\author{
David BARTOLINI, GOV/RDP
}

\begin{abstract}
There are many situations where the best outcome is reached through co-operation and co-ordination of agents' actions. Although this is the best collective outcome, economic agents may fail to implement such co-operative strategy. The reason for this failure may be lack of information about the gains from co-operation, or lack of capacity to implement the co-operative strategy. The present work focuses on two obstacles to co-operation that are linked with the incentives of the economic agents, and that are present even when the problems of information and capacity are taken care off. The two obstacles are the incentive to free ride and the strategic risk. The former stems from the possibility of obtaining gains without paying the associated costs (which are incurred by the agents that decide to co-operate); the latter is the risk of being the only one (or among the few) that acts co-operatively, so that the agent pays the costs but obtains less than what it would be feasible had other agents decided to co-operate. In this setting, using a game theoretical approach, we distinguish several cases of co-operation failures according to the relevance of those two obstacles. The analysis is then applied to contractual design and financial incentives. The overall message is the importance of identifying the source of co-operation failure in order to devise an effective policy to induce co-operation. It may not be enough to tell people (and institutions) that they should co-operate because it is in their interest, it is necessary to identify the incentives that shape agents' decisions and are responsible for co-operation failures.
\end{abstract}

\section{JEL Classification: C70, C72, D86}

Keywords: game theory, co-operation and co-ordination failure, economic incentives

* I wish to thank Joaquim Oliveira Martins, Enrique Garcilazo, Rudiger Ahrend, Bill Tompson, Karen Maguire, Catherine Gamper, and Emily Farchy for useful comments and continuing support during the drafting of the working paper, as well as participants to the GOV/RDP internal seminar on 13 July 2012. The views expressed are those of the author and do not reflect those of the OECD or its member countries. 


\section{TABLE OF CONTENTS}

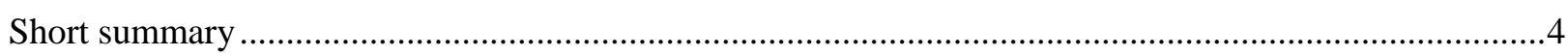

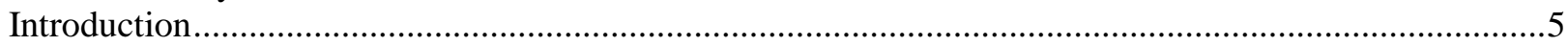

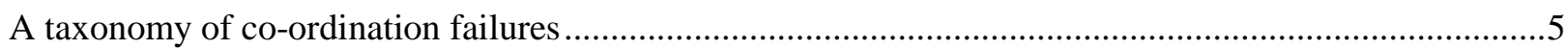

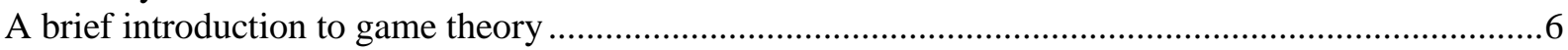

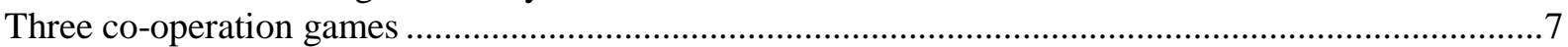

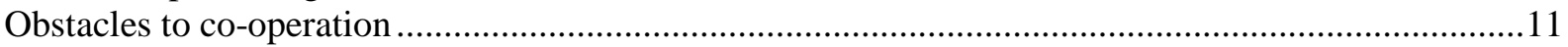

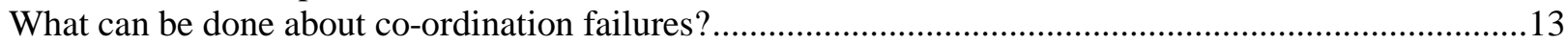

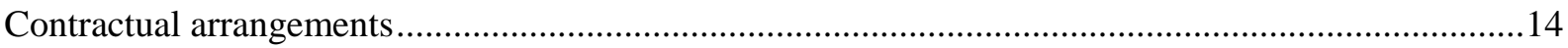

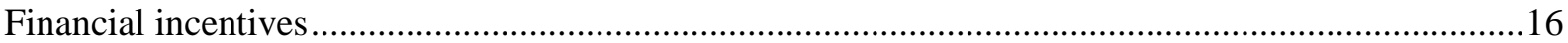

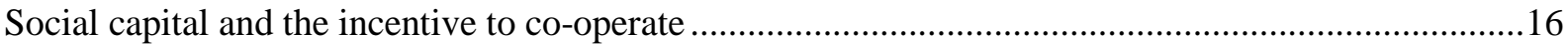

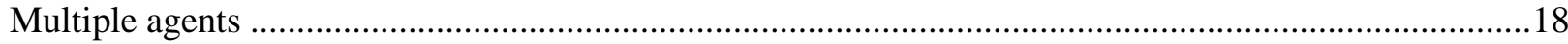

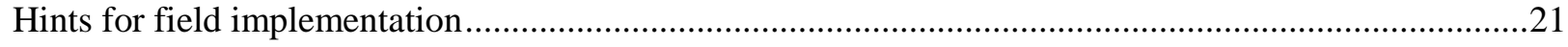

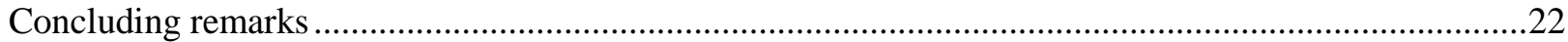

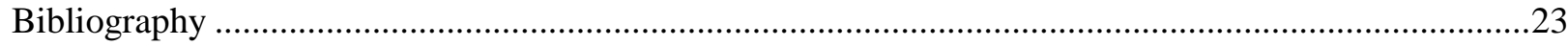

\section{Tables}

Table 1. Quality of governance and citizens' trust........................................................................17

\section{Figures}

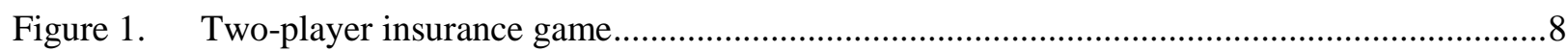

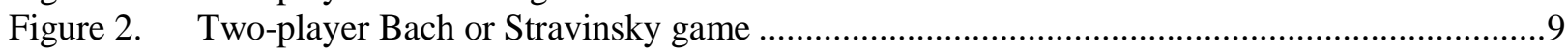

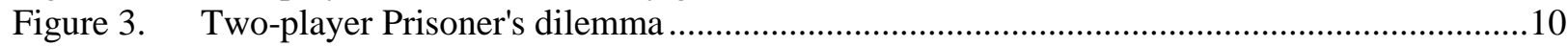

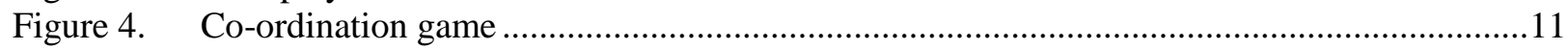

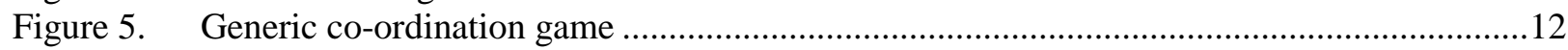

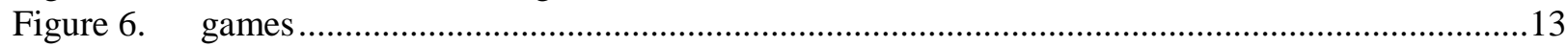




\section{Short summary}

The success of most economic policies depends on the interaction among people, entrepreneurs, policy makers, etc. There are many examples of skilfully designed policies which do not achieve the expected result due to the absence of co-operation amongst institutions and economic agents. For instance, a policy scheme designed by the central government to promote innovation requires the co-operation of the local government for its implementation; the possibility to provide a service at an economic efficient scale may depend on the co-operation between several municipalities.

Sometimes people do not realise that there are gains from co-operation; in other cases, they do not know how to co-operate, lacking the necessary capacity. Tackling those problems - although necessary may prove not sufficient to induce co-operation. Even when people realise that there are benefits from co-operation and know how to implement the co-operative strategy, they still face two obstacles that may hinder their ability to co-operate: the incentive to free ride and the strategic risk. The former stems from the possibility of obtaining gains without paying the associated costs (which are incurred by the agents that decide to co-operate); the latter is the risk of being the only one (or among the few) that acts co-operatively, in this case the agent pays the costs but obtains less than what it would be feasible had the rest of the players decided to co-operate.

In this setting we distinguish several cases of co-operation failures according to the relevance of those two obstacles. The analysis of the incentives to co-operate is instrumental to the definition of a policy that can actually induce co-operation whenever it is optimal to do so. There are many mechanisms that can be used to facilitate co-operation, among them contractual arrangements and financial incentives have a prominent role in policy making. A monetary transfer (such as a subsidy to firms) reduces the strategic risk, but it is not sufficient to induce co-operation if there is a strong incentive to free ride on other people's actions; in fact, in case of high gains from free riding, the subsidy could either be not effective or induce only temporary co-operation (with agents going back to the non co-operative action as soon as the subsidy ends). A contractual arrangement should focus on verifiable requirements if the main obstacle to co-operation is the incentive to free ride, because the co-operative strategy must be enforced with some sort of penalty; by contrast, if the failure mainly originates from the strategic risk the contract should be devised as a mean to share the information and shape agents' beliefs, regardless of verifiability.

The analysis is extended to consider the interaction amongst more than two economic agents. The possibility of reaching partial agreements (co-operation within a subset of economic agents) characterises this environment. The larger the number of players in the partial agreement, the larger the incentive to free ride and the lower the strategic risk.

The overall message stemming from the analysis is the importance of identifying the source of cooperation failure in order to devise an effective policy to induce co-operation. It may not be enough to tell people (and institutions) that they should co-operate because it is in their interest, it is necessary to identify the incentives that shape agent's decisions and are responsible for co-operation failure. 


\section{Introduction}

In the analysis of co-ordination a big role is played by the strategic interaction between economic agents: the action of one player triggers a reaction by another one, and so forth. The game-theoretic approach allows a systematic explanation of this matter, as it focuses on the definition and study of the way in which economic agents interact with each other.

The aim of the present work is to provide a method to better understand the problems of co-ordination that agents face in many real-life situations. The method is based on the definition of the "state of the world" situation, by identifying the incentives that drive agents' behaviour and determine the way in which they interact with each other. This is instrumental to the identification of the type of co-ordination failure and to the definition of appropriate mechanisms to facilitate co-operation.

There might be many reasons for this inability to co-operate. For instance, the parties may be uncertain about the size of the mutual benefit, or ignorant of the existence of the co-operative strategy. There is no doubt that lack of information and lack of capacity can hinder co-operation. Nevertheless, even once we solve these problems, players may still fail to co-operate - as is shown in the next section. In the present work, we focus on situations where all agents gains from co-operation, and any agent would prefer the co-operative outcome to the non-co-operative outcome; they all know what are the gains from all possible outcomes of the game, hence they know that by co-operating they are better off. There is complete information, and players know how to co-operate (no capacity constraint). In other words, the analysis focuses on some basic problems of co-ordination that are likely to arise in any strategic situation, even though, in many real-world scenarios they are not the only problems.

The first part of the work introduces a taxonomy of co-ordination failures based on the incentives to co-operate that economic agents face. It is possible to identify two basic obstacles to co-operation: the incentive to free ride, and the strategic risk. The former is the gain of exploiting the co-operative behaviour of other agents, receiving a gain from their actions without paying the costs (i.e., without contributing); the latter is the loss agents incur when deciding to co-operate while other player(s) do not. The main message is that a policy that tackles only one of the two obstacles is not sufficient to induce co-operation. In fact, any policy should be tailored on the degree of free riding and strategic risk that characterises a specific situation.

The second part of the analysis focuses on two mechanisms usually employed to cope with co-ordination problems: contractual arrangements and monetary transfers. The analysis describes how these mechanisms deal with co-operation obstacles discussed in the theoretical analysis. Finally, the analysis is broadened to take into account the possibility of partial co-operation, which emerges when more than two players interact, so that a co-operative agreement can be reached among a subset of agents.

There are two important issues that are left out of the analysis: strategic interaction in a dynamic setting, which introduces problems of credibility and dynamic inconsistency; and the analysis of the process of negotiation between the parties. The former is important because real-world situations take place in time; agents often meet and interact more than once. The latter is important to determine the way in which co-operation is achieved, and how the parties share the benefits from co-operation.

\section{A taxonomy of co-ordination failures}

At the heart of the game-theoretic approach there is the structure of the game, which is the description of the strategic interaction in terms of players' identity, available strategies, and rewards (that in the jargon of game theory are called payoffs) over the possible outcomes of the game. The analysis of the interaction among players is based on two tools: the concept of equilibrium and the concept of Pareto efficiency. The 
former provides a solution to the game - i.e., the interaction of the economic agents -, which allows to study how the performance of system changes when some characteristics of the economic environment change. The concept of equilibrium used is the Nash equilibrium, defined by John Nash in $1950 .{ }^{1}$ The second concept - Pareto efficiency - defines the optimality of the solution in terms of the payoffs accruing to each player. An outcome is Pareto efficient if there is no other combination of strategies that gives everybody a higher payoff or at least to one player a higher payoff while leaving the others' payoffs unchanged. ${ }^{2}$ This concept allows to restrict attention to the situation in which the co-operation is actually mutually beneficial. It is only in these cases that a co-operation failure arises, as the inability of the parties to co-operate in order to obtain the mutual benefit.

It is worth noting that there might be some economic situation where an equilibrium fails to exist, and where it is not possible to define a Pareto efficient outcome. As noted by Baumol and Oates (1988), if the objective function of players (even one of them) is not concave, then the aggregate payoff is not concave and there is no possibility to define a maximum; as a consequence, it is not possible to define a Pareto optimal allocation. In the cases in which a Pareto efficient allocation does not exist, we can hardly talk of co-ordination failure (at least at the theoretical level). In many instances, not necessarily confined to the private sector, competition produces a higher payoff than co-operation. For instance, competition may provide the necessary incentive for agents to be efficient.

The strategic interaction is modelled as a game, where economic agents, called players, interact. The outcome of the game is the reward, called the payoff, which each player receives as a result of the interaction of their actions. Co-ordination failures are classified according to the incentive to co-operate of each player, which depends on their payoffs. In the following, the terminology and main features of the game-theoretic approach is introduced in some detail.

\section{A brief introduction to game theory}

The interaction among economic agents is modelled as a game, where the economic environment is represented by the rules of the game, which define the set of players, the actions each player can take, and the payoffs associated with any combination of such actions. This detailed definition of the players and the rules governing the interaction represents one of the main strengths of the approach, for it allows a better understanding of the impact of each element on players' decisions. An introduction to the game theoretic approach is provided, among others, by Kreps (1990), Gibbons (1992), and more recently Osborne (2004).

In general, economic agents' behaviour depends on the institutions, the legal system, the set of property rights, etc., that define the economic environment. In the game-theoretic approach agents' choices do not only depend on the economic environment but also on what other agents do. It is in this sense that the term strategic behaviour, or interaction, is used. In fact, this is at the heart of any co-ordination issue. The term "players" of the game refers to a vast category of entities that have the possibility to make a choice (to take an action in the game); for instance, organisations such as firms, trade unions, political parties, or governmental agencies, can be players. The combination of all possible actions determines players' payoff, which is the reward (either in monetary terms or utility level) accruing to each agent.

1. A description of this concept is provided in the next section; for an introduction to the game theoretic approach see Gibbons (1992) and Osborne (2004). The seminal paper where the concept of equilibrium is developed is Nash (1950).

2. This concept represents the most "objective" way of evaluating the performance of the economic system, as it does not require any direct comparison between the payoffs of economic agents. By contrast, evaluating the outcome in terms of "equity" would require a judgment about the relative wellbeing of all agents. 
The outcome of the game is defined by the combination of strategies (one for each player) that constitute the equilibrium. In the following we use the concept of Nash equilibrium, which is the best known solution concept for games where players choose their actions non-co-operatively. The term "nonco-operative" game refers to the assumption that players choose their strategy according to the maximisation of their payoffs without taking into account the effect on other players' payoffs. The Nash equilibrium is based on the idea of best responses of a player to any possible action of the other players. The equilibrium is given by the combination of strategies where no player has an incentive to unilaterally chance his/her own strategy.

A postulate that game theory shares with most of the economic literature is the assumption that economic agents do their best to achieve the maximum result for themselves in any interaction with other players, i.e., that players are rational and self-interested. By doing so, the analysis abstracts from problems in which people are incompetent, or do not want (or know how) to maximise their payoffs. In fact, some problems of co-operation may depend on the incapacity of the players to understand the rules of the game and act accordingly. The lack of rational behaviour, however, is not lack of information. The two are distinct problems. An agent would still maximise his/her payoff given the information set available. Thus, the lack of co-operation because of a lack of information is perfectly compatible with the assumption of rational players.

It is worth acknowledging that there are other motives that can lead to co-operation other than rational behaviour. The literature on behavioural economics and psychology identify reciprocity, ethical and moral motives as drivers of co-operation between individuals (see Axelrod, 1984). In a later section we will consider the impact of reciprocal trust on co-operation incentives.

Finally, it is important to note that the structure of the game (i.e., the rules) cannot be changed by the players. In fact, the players can change the rules of subsequent games. For instance, the strategic situation can consists of two distinct moments. A first stage where players interact in order to decide the rules (like a constitutional assembly) under which the subsequent interaction will take place, and a second stage where players interact according to the rules defined in the previous stage.

\section{Three co-operation games}

The taxonomy of co-ordination failure is based on the incentives of economic agents to pursue a co-operative strategy. Those incentives depend on the preferences of the agents for different outcomes of the interaction. In economics, the term preference is used to define a ranking of possible results in terms of an agent's wellbeing. In the context of game theory, preferences are such that players prefer higher payoffs to lower ones and choose the strategy that would lead to the highest payoff, given their beliefs about other players' actions.

In the following, we present a simple version of the game where there are only two players, and each player can only undertake one of two actions. The limited number of available actions does not affect the main results of the analysis, which is easily extendible to the case in which each agent has a larger number of options. The presence of more than two players enriches the game with the possibility of achieving cooperation among a subset of players (partial co-operation), which will be dealt with in a later section. Neither restriction, however, affects the results in terms of obstacles to co-operation. As regards the number of players, it must be finite; nevertheless, the analysis can be applied to an infinite population of players, as long as they can be grouped into finite subsets (for instance, according to their level of income).

The strategic interactions are presented in a matrix where the columns correspond to the actions one player and the rows to the action of the other player. The cells of the matrix represent the payoffs for each 
possible combination of the actions of the two players; inside each cell, the number on the left represents the payoff of the row player, while the number of the right the payoff of the column player.

\section{Pure co-ordination game}

The pure co-ordination game, also known as the insurance game, is a strategic situation where the highest payoff is associated with the same outcome for both players. Agents' preferences are such that they prefer it above all other possible outcomes. A problem of co-ordination arises when there is more than one equilibrium outcome.

Figure 1. Two-player insurance game

\begin{tabular}{|c|c|c|}
\hline & A & B \\
\hline A & 2,2 & 0,0 \\
\hline B & 0,0 & 1,1 \\
\hline
\end{tabular}

In the game described in Figure 1, there are two Nash equilibria, the combination of strategies $\{\mathrm{A}, \mathrm{A}\}$ and $\{\mathrm{B}, \mathrm{B}\}$. The outcome of the equilibrium $\{\mathrm{A}, \mathrm{A}\}$ is, however, preferred by both players to any other outcome, i.e., it is a Pareto efficient allocation. A problem of co-ordination arises because of each player's uncertainty about the action to be taken by the other player. The strategic uncertainty lies in the fact that choosing action A when the other player chooses B results in the lowest possible payoff. Therefore, if a player believes the other will choose B, the optimal choice is indeed B.

This type of problem has been extensively investigated in the economic literature and refers to situations where players' actions are highly complementary. This is the case for co-ordination externalities, where actions must be taken simultaneously in order to be profitable. For instance Murphy et al. (1989) show how a simultaneous expansion of many sectors can be economically sustainable, while the development of a sector in isolation is not. Therefore, each firm fears that the other would not invest and as a result its initial investment would be unproductive. There are complementarities also in government's policies, which when undertaken in isolation may produce a worse result than the status quo. This might be the case when several government bodies are involved in the creation of implementation of one or more policies.

Choosing the Pareto efficient equilibrium seems easy in this situation. However, the problem is not trivial as the number of player involved increases. Moreover history plays an important role, because it influences the formation of beliefs (expectations) about other players' choice. Once a bad equilibrium is reached, it tends to shape beliefs in such a way that it is not convenient (i.e., rational) for players to change their strategy. A famous example relates to the computer keyboard design, which currently is known as "QWERTY" by the arrangement of the first six letters in the top row. The current layout does not minimise the typist's effort, nevertheless the QWERTY system has been in place for many decades, and there is no intention to change it. ${ }^{3}$ This is so, not only because changing from one keyboard layout to another one is difficult, and requires costly re-training of the typist, but also because any apprentice would choose to be trained on the QWERTY standard (this is called in the literature a bandwagon effect). Consider a game between prospective typists and firms, where the typists decide which method to be trained for, and the firms which type of keyboard to buy, it is likely that they both choose the QWERTY system, hence converging to the lower equilibrium. The potential typist, by choosing to be trained for a more efficient

3. This example is reported by the economic historian Paul David (1985), which focused on technology adoption and lock-in factors. 
system, risks not matching the firms' standard (QWERTY keyboards); similarly, the employer that opts for a more efficient keyboard, risks not finding any typist that can use it.

In this example each individual or firm cannot change the equilibrium, it is only a co-ordinated action by all agents, or a considerable share of agents that can switch to the efficient equilibrium. The incentive to switch to a better equilibrium can be fostered by suitable government policies, for instance, by taking care of the costs of retraining to the new technology, or providing financial incentives for firms to adopt the best technology, so that demand for typist trained on the best technology is created. The key point is that once a critical mass of people is "converted" to the most efficient technology, the intrinsic advantage of this technology would be enough to reach the Pareto efficient equilibrium.

\section{Choosing between Bach and Stravinsky}

Consider the strategic situation where two people wish to go out together. Two concerts are available: the Brandenburg concertos by Bach, and the Symphony in three movements of Stravinsky. One person prefers Bach while the other prefers Stravinsky, but both persons prefer to go to the concert together rather than alone. For instance, the preferences of the person that loves Bach are ordered in the following way: going to the Bach concert with the other person, going to the Stravinsky concert with the other person, going to the Bach concert alone, going to the Stravinsky concert alone. The key element of this strategic situation is that both players prefer to go to the concert together (even though is not a concert of their preferred author) rather than going alone to the concert of their preferred composer.

The Bach or Stravinsky game, also known as Battle of the Sexes, is an example of strategic interaction in Nash's PhD thesis. It describes a strategic situation where co-operating produces the highest payoff, but contrary to the pure co-ordination game, each player would like to co-operate in a different way.

\section{Figure 2. Two-player Bach or Stravinsky game}

\begin{tabular}{c|c|c|} 
& \multicolumn{1}{c}{$\mathrm{B}$} & \multicolumn{1}{c}{$\mathrm{S}$} \\
\cline { 2 - 3 } $\mathrm{B}$ & 2,1 & 0,0 \\
\cline { 2 - 3 } $\mathrm{S}$ & 0,0 & 1,2 \\
\cline { 2 - 3 } & &
\end{tabular}

Figure 2 provides a visual representation of such strategic situation, where $B$ is the action of going for Bach, while $S$ is the action of going to a Stravinsky concert. The matrix of payoffs shows that if one player goes for Bach and the other goes for Stravinsky, their payoff is zero. It is only if they co-ordinate in either Bach or Stravinsky that a payoff higher than zero is achieved. The difference with the pure co-ordination game rests on the fact that the row player prefers both of them listening to a Bach concert, while the column player prefers both of them to enjoy a Stravinsky concert.

Both strategy, i.e. $\{B, B\}$ and $\{S, S\}$ are equilibria of the game. The problem of co-ordination is again strategic uncertainty, with the twist that each player has his own preferred equilibrium outcome. This type of strategic interaction arises every time players prefer to co-ordinate their actions rather than not, but there is more than one possible co-operation strategy and each player has his/her own preferred strategy.

This is the case of a public project that affects two communities, for instance a bridge connecting two towns. The cost of the project is such that neither community can afford the construction of the bridge by itself. There are two different materials that can be used to build the bridge, with the same total cost. One community prefers the bridge to be built using mainly wood, while the other prefers the bridge to be built using iron and steel. Both local communities prefer the bridge to be built rather than not, but each has its own preference on the material the bridge should be built with. 
The simple game-theoretical approach used in this work is not able to say much about this situation. In fact, the theory can only say that the players co-ordinate in one of the two equilibria, and that this equilibrium is Pareto efficient. There is no co-ordination failure in the sense used in this work, as both possible equilibria are Pareto efficient. In order to investigate some more the nature of the strategic interaction, we would need to investigate how the negotiation between the parties takes place and the selection of the equilibrium would depend on the bargaining power of the parties involved.

\section{Prisoner's dilemma}

The most studied strategic situation, in both political science and economics, is the prisoner's dilemma. Despite the name, this is a strategic situation that is common in many cases: tax co-ordination vs. tax competition; arm race; public good provision; common property resources (CPR); collusion among firms; etc. All these situations have in common the feature that, by deviating from the co-operative strategy, a player can obtain the maximum possible payoff. Therefore, there is an incentive to free ride on the co-operative action of the other player, that is, an agent can get some benefit without paying any cost.

Figure 3 describes this strategic interaction. Both players are better off if they co-ordinate on the cooperative strategy (Coop, Coop), than if they choose the non-co-operative action (Dev, Dev). The difference with the cases previously analysed is that each player can get a payoff higher than the co-operation strategy if he/she deviates, choosing action (Dev), while the other player is still on the co-operative strategy (Coop). This higher payoff is precisely the incentive to free ride on the other player's co-operation.

Figure 3. Two-player Prisoner's dilemma

\begin{tabular}{c|c|c|}
\multicolumn{1}{c}{} & \multicolumn{1}{c}{ Coop } & Dev \\
\cline { 2 - 3 } Coop & 2,2 & 0,3 \\
\cline { 2 - 3 } Dev & 3,0 & 1,1 \\
\cline { 2 - 3 } & &
\end{tabular}

The problem of co-operation arises because this strategic situation presents only one equilibrium, the non co-operative strategy (Dev, Dev). In fact, the choice of the action Dev is optimal for a player regardless of the choice of the other player. In other words, players know that co-operation is better than non co-operation, but by choosing the deviating strategy, they can get a larger payoff regardless of the action of the other player: that is, if the other player chooses Coop, then the payoff is 3 , if the other player chooses Dev than the payoff is 1 . By contrast, if a player chooses the Coop strategy, then he/she would get 2 if the other player chooses Coop and 0 if the other player chooses Dev. Since both players would reason in the same way, they would both play the strategy Dev which leads to a non-Pareto efficient outcome; both players would be better off by switching to the co-operative strategy.

The existence of free riding incentives rest on non rival benefits stemming from players' actions, i.e. the action of a player produces a favourable outcome for other players. For instance, in case of environmental protection, the decision to reduce polluting emissions by one country would favour also the neighbouring countries. Clearly, if all countries co-operate in reducing pollution the outcome is better than if no country reduces pollution. However, each country can deviate from this co-operative strategy, letting the rest engage in pollution abatement while enjoying the benefits. The prisoner's dilemma situation, therefore, arises each time the net benefit of reducing emissions is lower than the benefit of letting other countries do it. As a result, any country would prefer the non-co-operative strategy which leads to an inefficient outcome, no reduction of pollution. 


\section{Obstacles to co-operation}

The examples of strategic interaction described in the previous section have in common the fact that the aggregate payoff (the sum of both players' payoffs) associated with the co-operative outcome is higher than the aggregate payoff associated with any other combination of strategies. In this situation there must be some incentive to co-operate. The incentive, however, is not the same in every situation. In the case of a pure co-ordination game, co-operation is mutually beneficial, while in the prisoner's dilemma case there is also an incentive to free ride.

Identifying the different incentives that drive players' action is important for tackling co-ordination failure. For instance, in the case of pure co-ordination, any mechanism that allows players to co-ordinate on the desired solution, such as talking to each other, is enough to solve the co-ordination failure; by contrast, in the prisoner's dilemma case, talking is not enough, for the incentives are not aligned, i.e., the incentive to free ride on the other co-operative behaviour is still in place.

The main differences in the incentives to co-ordinate are best understood in the following game in strategic form, where there are two players with two actions: a co-operative action (соор) and a deviating (dev) action (this example is take from Weber, 2008).

Figure 4. Co-ordination game

\begin{tabular}{cc|c|c|} 
& \multicolumn{2}{c}{ Player 2 } \\
\multicolumn{3}{c}{ Coop } & Dev \\
\cline { 3 - 4 } Player 1 Coop & 2,2 & $0, x$ \\
\cline { 3 - 4 } & Dev & $x, 0$ & 1,1 \\
\cline { 3 - 4 } & & &
\end{tabular}

According to the value of $x$ we can have different problems of co-operation:

- for $x<2$, incentives are aligned, so that co-operation does emerge as a Nash Equilibrium of the game, but it is not the only one; the problem is how to achieve the efficient equilibrium;

- for $x>2$, incentives are less aligned; each player by deviating gets more than following the co-operation strategy.

It is clear that the incentive to co-operate is inversely related to the value of $x$. The lower is $x$, the higher is the incentive to co-operate. $X$ represents the payoff from deviating. If this payoff is lower than what received in case of co-operation, then there is no incentive to free ride. The relative magnitude of these payoffs plays a crucial role for the incentive to co-operate. The larger is $x$ (given the other payoffs) the more difficult is to achieve co-operation.

In order to capture the importance of the relative magnitude of payoffs, it is worth using an "index of co-operation", developed by some game theorists in the 60s (see for instance see Rapaport, 1967). This index represents a synthesis of the player's payoff for each possible outcome of the game. In the case analysed in the present section, there are: the payoff of co-operation (C); the payoff in case of non-co-operation $(\mathrm{N})$; the payoff in case of deviation $(\mathrm{D})$; and the payoff in case of co-operation while the other player deviates (L). Figure 5 shows this labelling of payoffs. 
Figure 5. Generic co-ordination game

\begin{tabular}{cc|l|l|} 
& \multicolumn{2}{c}{ Player 2 } \\
& \multicolumn{1}{c}{ Coop } & Dev \\
\cline { 3 - 4 } Player 1 Coop & $C, C$ & $L, D$ \\
\cline { 3 - 4 } & Dev & $D, L$ & $N, N$ \\
\cline { 3 - 4 } & & &
\end{tabular}

The index of co-operation is a function of those payoffs, $K=K(D, C, L, N)$, with the requirement that $C$ and $\mathrm{L}$ increase the index, while $\mathrm{D}$ and $\mathrm{N}$ decrease the index. This implies that an increase in the payoff associated with the co-operative outcome (C) or an increase of the payoff in case of being let down by the other player (L), increases the incentive to co-operate. By contrast, an increase in the deviation payoff (D) and on the payoff of the non co-operative outcome $(\mathrm{N})$ reduces the incentive to co-operate. Rapaport (1967) proposes some possible explicit formulas for this index, such as a quotient of linear polynomials,

$$
K=\frac{(C-N)}{[(C-N)+b(D-C)+g(N-L)]}
$$

More than the index, for the identification of the incentives to co-operate it is important the meaning of each polynomial. For instance, Ahn et al. (2001) label the polynomial $(D-C)$ as Greed, that is, the incentive to free ride; $(N-L)$ as Fear, the risk a player avoids when deciding not to co-operate; and $(C-N)$ as co-operators' gain, the difference between the non-co-operative outcome and the co-operative outcome. Clearly, the incentive to co-operate are lower the higher is Greed and Fear, and the lower are the co-operation gain. The interaction of those incentives is easily grasped if we rewrite equation (1) as

$$
K=\frac{(\text { coop gains })}{[(\text { coop gains })+b(\text { greed })+g(\text { fear })]}
$$

It is possible to identify two main obstacles to co-operation: the incentive to free-ride $(D-C)$, and the strategic risk $(L-N) .{ }^{4}$ These two obstacles characterise and distinguish the different cases of co-ordination failure, and should be taken into account when devising a policy to facilitate co-operation. Let us consider the prisoner's dilemma game described in figure 6 , the incentive to free ride is equal to $(5-4)=1$, and the strategic risk is equal to $(0-1)=-1$. A policy addressing only the free riding incentive - for instance by introducing a penalty equal to 1 , in case of deviation, so that $(D-C)=(4-4)=0-$ does not necessarily induce co-operation, the players still face a pure co-ordination game, represented by game (b) in Figure 6. This game has two equilibria, thus the achievement of the Pareto efficient outcome is not assured. ${ }^{5}$ On the other hand, if a policy only tackles the strategic risk - for instance, by providing a monetary incentive to players which co-operate - , so that $(L-N)=(1-1)=0$, the non-co-operative strategy is no longer a dominant strategy, but the efficient allocation is still not an equilibrium of the game. ${ }^{6}$ In fact, a monetary transfer that shields

4. The strategic risk is the inverse of the Fear payoff, it is in fact the difference between the non-co-operative strategy and the co-operative strategy, when he/she is the only one cooperating. In this sense, it is the risk involved with being let down by the other players.

5. It is worth noting that the penalty can be incurred either for choosing the strategy Dev while the other player(s) choose the strategy Coop, as assumed in text, or for choosing the strategy Dev irrespective of the choice of the other players. The difference is that in the latter case also the outcome of the non-co-operative strategy is affected, modifying the payoff of the strategic risk.

6. In the latter case, there are two equilibria that are Pareto efficient, but if we use the concept of social welfare (i.e., the sum of the payoffs of the players), we can say that the solution that maximises social welfare is not an equilibrium of the game. 
from the strategic risk, can create a perverse incentive, so that it is better to be let down by the other players than to have them co-operating.

Figure 6. Strategic interaction games

(In italics the equilibrium payoff)

\begin{tabular}{c|c|c|}
\multicolumn{1}{c}{} & \multicolumn{1}{c}{ Coop } & \multicolumn{1}{c}{ Dev } \\
\cline { 2 - 3 } Coop & 4,4 & 0,5 \\
\cline { 2 - 3 } Dev & 5,0 & $\mathbf{1}, \mathbf{1}$ \\
\cline { 2 - 3 } & &
\end{tabular}

(a) Prisoner's Dilemma

\begin{tabular}{c|c|c|}
\multicolumn{1}{c}{ Coop } & \multicolumn{1}{c}{ Dev } \\
\cline { 2 - 3 } Coop & $\mathbf{4 , 4}$ & 0,4 \\
\cline { 2 - 3 } Dev & 4,0 & $\mathbf{1 , 1}$ \\
\cline { 2 - 3 } & &
\end{tabular}

(b) policy tackles free riding

\begin{tabular}{c|c|c|}
\multicolumn{1}{c}{} & \multicolumn{1}{c}{ Coop } & \multicolumn{1}{c}{ Dev } \\
\cline { 2 - 3 } Coop & 4,4 & $\mathbf{1}, \mathbf{5}$ \\
\cline { 2 - 3 } Dev & $\mathbf{5 , 1}$ & $\mathbf{1}, \mathbf{1}$ \\
\cline { 2 - 3 } & &
\end{tabular}

(c) policy tackles risk of coop

It is not only the signs of these polynomials that are important; their magnitudes play a significant role, too. Two strategic situations can be both classified as Prisoner's dilemma, but the incentive to free ride can be substantially different. This matters for the definition of the policy in two ways. First, it is important that the mechanism is strong enough to offset the incentive to free ride, and second, a comparison between the two obstacles may serve as a guide for the policy maker to focus the policy instrument on the most important one. Any mechanism that aims at improving the situation must be devised in such a way that both the free riding incentive and the strategic risk are addressed.

In the following section we consider some mechanisms that are y employed to solve co-ordination problems and study their efficacy according to their impact on these two obstacles.

\section{What can be done about co-ordination failures?}

The solution to a problem of co-ordination can be external or internal to the set of players. In both cases the policy measure aims at changing the payoffs of the players, so that the co-operative outcome becomes the equilibrium of the game. In the case of external intervention, a third party, usually the State intervenes with regulations, taxes, or subsidies, in order to change the incentive of players. For instance, taxation imposed on the deviating action reduces the incentive to free ride - this is the idea behind Pigou's work on externalities and social welfare (Pigou, 1932). The solution, however, can also emerge as a spontaneous agreement among the parties involved. This is the idea behind Coase's theorem, which maintains that the agents would reach an agreement as long as there are no transaction costs (Coase, 1960); similarly, Ostrom (1990) considers the possibility that a problem of common resource usage could be resolved by an agreement amongst the parties involved. Their analysis shed some light on the situations where such "private" solutions emerge - typically it requires a strategic interaction that is repeated in time and that the parties can easily monitor.

The aim of the present work, however, is not to investigate the merits of one type of solution over the other. It is, rather, to understand how a solution operates in the context of each particular co-operation problem. Any instrument should be tailored to cope with the actual incentives. Whether the instrument can emerge from the presence of a third party or from the spontaneous agreement amongst the parties is outside the scope of the present work.

There are several instruments that can be used to cope with problems of co-ordination:

- explicit communication represents a form of communication that requires parties actively communicate to each other; this is opposed to non-explicit forms of communication such as the market (Farrel and Saloner,1988); 
- focal points relate to the existence of some specific strategies that everybody recognises as most probable to be played by the other agents; in other words, it provides a way to form beliefs on the other players' strategies (Schelling,1960);

- financial incentives are monetary payments that players receive in case they choose a particular action (usually the co-operative action);

- contractual arrangements provide a set of prescriptions that inform and in some cases limit the action of the players;

- $\quad$ repeated interactions create the possibility to establish a reputation, and most importantly to punish deviations from the co-operative strategy;

- formal and informal norms refer to the legal system and the presence of social norms that guide the behaviour and, thus the formation of players beliefs; in this regard, the level of trust in society helps to solve problems of co-ordination;

- insurance provides a safety net in case the co-operative strategy is not matched by the other player(s);

- $\quad$ a hierarchical structure: it provides an environment that can help players form beliefs about the way other players would make their choices.

Given that the ultimate goal of this work is to provide a framework for the analysis of co-ordination in a policy making context, the focus is on contractual arrangements, and financial incentives. These instruments are widely used in many cases where policy makers are involved.

\section{Contractual arrangements}

A contract is an agreement between two or more agents that regulates some aspects of the interaction between the parties. It provides insurance against the risk of deviation from the co-operative action of the other parties. There are, however, other functions that the contract may perform. For instance, Hart and Moore (2008) consider the possibility that a contract could provide a reference point for the parties, serving as a yardstick to measure the ex-post fairness of their actions. Furthermore, a contract can serve as a mean to share information through the parties about the likely action that each agent will undertake. For instance, an OECD (2007) study investigates how contracts can be used to manage the relationship between levels of government.

This instrument has been widely analysed in the economic literature (see for instance Bolton, 2005), focusing on so called "complete" contracts, where any possible future state of the world can be contracted. More recently economists have begun to grapple with the fact that contracts are intrinsically incomplete, in the sense that it is either impossible or too costly to consider all possible future states of the world, or alternatively that the prescriptions of the contracts cannot be verified by a court of law (see Hart and Moore, 1999).

There are two things that matter in our discussion of co-ordination failures. The first is that the verifiability of contracts may depend on the ability of a third party to know and enforce the contract. This possibility can be more or less costly (feasible) according to the quality and availability of third party enforcement (for instance, an efficient judiciary system). The second issue relates to the content of the contract, part of the literature maintain that only verifiable clauses should be part of the contract because non verifiable items will be disregarded by the parties, thus resulting in a waste of resources. 
The importance of verifiable statements and, hence the importance of enforceability is larger the larger is the incentive to free ride; by contrast, the strategic risk can be reduced by the information embodied in the contract, even if it is not verifiable by a third party. In a situation characterised mainly by the strategic risk, the enforceability of the contract is not a central issue, thus the information necessary for the parties to co-operate should be part of the contract, irrespective of its verifiability. By contrast, in order to reduce the free rider incentive, enforceability is crucial; it is the punishment arising from a violation of the terms of the contract that reduces the incentive to free ride, by reducing the payoff of deviation (D). The punishment for a violation of the contract depends on the verifiability of the terms violated by a third party.

The efficacy of contractual arrangements, therefore, depends on the degree of law enforcement and on the magnitude of the obstacles to co-operation. A contract can be effective to induce co-operation when the incentive of free riding is low, while being totally ineffective in situations where the parties have a strong incentive to free ride. On the one hand, if the contract contains mostly non verifiable clauses, then the free riding incentive is not tackled. On the other hand, if the contract contains only enforceable clauses, while other important pieces of information are not included because not enforceable, then it may not successfully address the strategic risk. As we have seen in the previous section, reducing the free riding incentive may lead to a situation of strategic uncertainty.

In most real-world situations, the strategic interaction between players takes place in time. In this case there could be a problem of dynamic inconsistency. This is the case when today's plan of action for a future period is no more optimal when the future period arrives. This introduces problems of commitment and credibility, as shown by Schelling (1960). A player that commits today to a particular action to take in the future, may not be credible if players anticipate that that is not his/her optimal strategy when the time to take the action arrives. The problem is that today's incentives may differ from tomorrow's incentives, so that ex-post incentives reduce the credibility and possibility to commit today to take a particular action in the future. If a commitment is not credible, then players will behave as if there were no commitment at all. A contract can enforce a commitment, but it must be credible, i.e., there should not be subsequent renegotiations of the terms and conditions.

There are several examples of such problems. From the well-known inter-temporal inconsistency of inflation targeting, which led to the separation of the monetary policy from the direct control of the government (in charge of the fiscal policy), ${ }^{8}$ to the hold-up problem that affects investment decisions, whereby an agent refrains from the optimal level of investment for the risk of being stripped of part of the future returns. Every time there is a commitment (inter-temporal) problem, co-ordination is not achieved and mechanisms need to put in place. The contractual arrangement, however, may suffer of lack of credibility. In particular, a trade-off between commitment and flexibility characterises most situations. The more flexible is the contract, the better it addresses shocks that may occur in future periods, but as a consequence the credibility of the commitment is reduced.

The elements of this trade-off find a direct match with the two elements that characterise coordination failures: the incentive to free ride and the strategic risk. Commitment is crucial to reduce the incentive to free ride, the parties must believe that the effect of a deviation will be met with the prescriptions in the contract; otherwise, they will behave as if it were nonexistent. By contrast, the strategic

7. In case of repeated interaction among the parties, punishment can be implemented directly by the parties. The crucial assumption is, however, that there is no foreseeable end date to their relationship. In fact, if the parties know when their relationship will end, the punishment mechanism can no longer be implemented by the parties, and the availability of third-party enforcement becomes relevant.

8. Kidland and Prescott (1977) showed that the main problem in the coordination of monetary and fiscal policy was the absence of credibility of the inflation target monetary policy. 
risk is better addressed with a flexible contract that allows the parties to adapt to different situations and co-ordinate future actions.

In conclusion, the way in which a contract should be devised depends on which element of the strategic situation is predominant. If the incentive of free riding is predominant (as in the Prisoner's Dilemma game), then the credibility of the contract and the verifiability of the prescriptions should be at the centre of the solution; by contrast, if free riding is not an issue, than the contract should serve more as a tool for shaping the beliefs of players, and the elements of information content and flexibility to accommodate for future events (shocks) should be central.

\section{Financial incentives}

The idea that financial incentives, such as transfers and subsidies, can help economic development has been at the centre of policy intervention since Pigou's analysis of the remedies to externalities (Pigou, 1932). This is also at the heart of EU policies to promote economic development (i.e., cohesion funds). The question we are interested in the present work is to what extent monetary incentives help to cope with co-operation problems.

Monetary incentives help to reduce the risk associated with the co-operative strategy when other agents decide not to co-operate. This is likely to be sufficient to induce co-operation, as long as the gains from free riding are low. On the contrary, if the incentive to free ride is high, the reduced strategic risk may not be enough to overcome the gains from deviation. In this case, the non-co-operative strategy is no more dominant, but remains one of the possible equilibria of the game. This is because the monetary incentive makes it indifferent for a party to react to the other party with a deviation or co-operation (in case of co-operation the subsidy compensates the strategic risk).

When the gains from free riding are initially low the strategic situation becomes similar to the pure co-operative game, and the initial monetary incentive can be enough to induce. ${ }^{9}$ However, if the gains from free-riding are high the monetary incentive does not prevent people from deviating. In fact, there are many cases in which co-operation is initially triggered by monetary incentives, but once the financial help ends, parties go back to a non-co-operative behaviour.

In conclusion, the financial incentive is very powerful when the strategic situation is characterised by low returns from free riding. Otherwise, either it is not effective, or the co-operation is likely to end with the financial incentive.

\section{Social capital and the incentive to co-operate}

The environment in which economic agents interact influences their willingness to co-operate. Putnam (1993) argues that the difference in economic development between the south and the north of Italy depends on the different level of social capital. ${ }^{10}$ In the words of Putnam, spontaneous co-operation is easier when citizens trust each other and expect reciprocity. This is clearly an important element that can facilitate co-operation.

The analysis conducted in the previous sections allows us to be more specific about the way in which trust affects the incentive to co-operate. In fact, it is necessary to investigate how the level of trust affects

9. This is the idea behind the big push (Murphy et al. 1989), and all situations where there is a high degree of complementarity amongst the actions of the players.

10. Putnam defines social capital as "features of social organization, such as trust, norms, and networks that can improve efficiency of society by facilitating coordination actions" (Putnam, 1993, p. 163). 
the strategic risk and the free-riding incentive. The former is likely to be lower the higher citizens' trust because they expect the other players to co-operate. This reciprocal belief allows them to overcome the risk of being the only one that co-operates. By contrast, the incentive to free ride is not necessarily alleviated by the reciprocal trust. It is more the social stigma that comes from deviation that could reduce this incentive. The mere level of trust does not reduce the incentive to free ride.

OECD (2013) looks at the formation of rural-urban partnerships in selected regions (OECD, forthcoming). From the comparison of information gathered in several regions, it emerges that the level of co-operation varies quite a lot. For instance, co-operation (in the form of rural-urban partnerships) seems to be stronger in the Netherlands than in Portugal. Amongst the many factors that could explain this difference, the level of reciprocal trust seems to be quite striking.

Table 1. Quality of government and citizens' trust

\begin{tabular}{|l|l|lllll|l|}
\hline Country & Region & EQUI100 & quality & impart & corrupt & regqual & trust \\
\hline Netherlands & Noord-Nederland & 97.61 & 1.36 & 1.55 & 1.58 & 1.76 & 47.30 \\
& Oost-Nederland & 87.90 & 1.03 & 1.20 & 1.08 & 1.30 & 64.14 \\
& West-Nederland & 89.96 & 1.07 & 1.07 & 1.42 & 1.39 & 53.16 \\
& Zuid-Nederland & 85.69 & 0.94 & 0.94 & 1.17 & 1.19 & $\mathbf{5 0 . 0 0}$ \\
\hline Portugal & Norte & 54.68 & -0.45 & -1.31 & -1.17 & -1.15 & 21.15 \\
& Algarve & 66.21 & -1.27 & -0.31 & 0.06 & -0.60 & 26.09 \\
& Centro & 61.05 & -0.49 & -0.76 & -0.91 & -0.85 & $\mathbf{1 9 . 7 1}$ \\
& Lisboa & 64.74 & -0.59 & -0.63 & -0.49 & -0.67 & 22.77 \\
& Alentejo & 77.74 & -0.09 & -0.05 & 0.01 & -0.05 & 17.78 \\
& Região Autónoma dos Açores & 72.82 & -0.27 & -0.38 & -0.09 & -0.29 & 19.54 \\
& Região Autónoma da Madeira & 67.76 & 0.12 & -0.80 & -0.67 & -0.53 & 23.85 \\
\hline
\end{tabular}

Table 1 shows some data on the quality of government and the level of trust, measured at the subnational level. ${ }^{11}$ It is clear that both the indicators of government quality and the level of trust are much higher in the Netherlands than in Portugal. Focusing on the two regions where the Dutch and the Portuguese case studies were conducted (Zuid-Nederland and Centro), it emerges that the level of trust in the Dutch region is more the three times the level of trust in the Portuguese region. In Portugal, where the level of trust is low, there are a lot of obstacles to co-operation, resulting in a form of co-operation where the only aim is to apply for EU funding. In the Netherlands, co-operation is deeper and with fewer conflicts. For instance, municipalities were able to co-operate on the candidacy of Eindhoven as 2018 European capital of culture.

11. The quality of governance indexes are derived from survey questions to a sample of citizens in every region. EQUIIOO is an indicator that goes ranges from 0 to 100, and represents a synthesis of all the other indicators and the quality of governance indicator collected by the World Bank. The indicators quality, impart, and corrupt represents the results of survey questions where people were asked about quality, impartiality and corruption level in public education, health services and law enforcement. Regqual represents a synthetic indicator of the previous three indicators. Finally, the indicator of trust is based on survey questions conducted by the World Value Survey, and represent the answer to the question: Generally speaking, would you say that most people can be trusted or that you can't be too careful in dealing with people? More information about the survey is available in the webpage of the Quality of Government Institute at the University of Gothenburg (http://www.qog.pol.gu.se). 
It is also worth noting that the original aim of the partnerships in both countries was mainly related to getting access to external funds (national or EU funds). In these cases the incentive to free ride is quite low, a deviation would exclude the player from any fund. In other terms the object of the co-operation is not a public good.

High levels of reciprocal trust, however, are not a panacea for the incentive to free ride. When the object of co-operation is non rivalrous (i.e., it is a public good), co-operation becomes difficult also in countries where citizens have a high degree or trust. ${ }^{12}$

\section{Multiple agents}

Most real-life situations are characterised by interaction among more than two agents. The main difference with the two-player case is the possibility of an intermediate outcome in terms of co-operation, that is, only a subset of players adopts the co-operative strategy. This situation is referred to as partial co-operation.

A recent stream of the game theoretic literature has focused on the study of co-operation amongst a large number of players, defining the co-operative strategy as a coalition between players. This coalition is actually an agreement to implement the co-operative strategy (see Ray, 2007, for a survey of the literature). The main focus is on players' incentive to be part of a coalition, and what happens to the agreement when one or more agents deviate, thus studying the features that facilitate the co-operation among players. In this context, when all agents are part of the same coalition, we have full co-operation (which is the Pareto efficient outcome), while coalitions among a subset of players is defined as partial co-operation and leads to a non Pareto efficient outcome. The latter, however, is better than the case where no player adopts the co-operative strategy.

The possibility to achieve partial co-operation influences both the incentive to free ride and the strategic risk. The incentive to free ride depends on the payoff in case of deviation while the other players co-operate; thus the incentive depends on the number of players that decide to co-operate. The larger the number the higher is the payoff from free riding because more of the public good is provided. Furthermore, when a player contemplates a deviation he/she should take into account whether other players would decide to deviate as well, because this impact on the size of the remaining partial coalition, and hence on the size of the gains from free riding.

The strategic risk is reduced by the possibility of players to form a partial coalition. This is because for the player that contemplates whether to co-operate there are now three possible scenarios: all players co-operate, no player co-operates, and some players co-operate. It is the latter, not available in the twoplayer case, which reduces the strategic risk. After all, a player might be willing to co-operate even if he/she does not expect all of the players to co-operate, as long as he/she expects a sufficient sub-set of them to do so.

One of the main implications in terms of policy is whether or not to favour the formation of partial coalitions. The answer is not trivial. There are at least three possible cases: the case in which the partial coalition is the maximum level of co-operation that is possible to achieve; the case in which the formation of partial agreements is instrumental for reaching a more comprehensive agreement, usually with players joining in subsequent periods; and the case in which reaching a partial agreement may hinder the achievement of a comprehensive agreement.

12. In talks with representative from the BrabantStad partnership (Netherlands), it emerged that while co-operation for attracting funds was successful, the members of the partnership were not able to reach a co-operative decision on where to establish a commercial centre. 
In the present work, we do not provide a detailed explanation of those cases. Nevertheless it is worth mentioning that in the presence of a low incentive to free ride, but a large strategic risk, then allowing partial agreements may pave the way to a general agreement. By contrast, if the situation is characterised by a high incentive to free ride, the possibility of reaching partial agreements are likely to prevent full co-operation (i.e., co-operation amongst all players). This is because the incentive to free ride increases with the number of players that decide to form a partial coalition, so that blocking the possibility of partial agreements, and thus reducing the incentive to free ride, may be the best policy to reach full co-operation. For instance, if the public good at stake can be easily provided by a small number of agents and it benefits everybody else (such as agreements on the reduction of $\mathrm{CO} 2$ emission), the benefit for countries that decide to stay out of the agreement increases with the number of countries that enter the co-operative agreement. One way to reduce the incentive to free ride is to prevent the possibility of reaching partial agreements, as this reduces the benefit from deviation.

In a recent contribution Bartolini and Zazzaro (2011), show that in games with positive externalities (i.e., where a public good is involved), a policy which makes partial agreements less profitable increases the possibility of reaching full co-operation. The theoretical model was applied to antitrust policies, showing that an increase in the level of penalty for collusive behaviour does not monotonically reduces collusive behaviour.

\section{Example 1: Strategic interaction with public goods}

Ray and Vohra (2001) look at the incentives that drive the production of a public good which benefits all players but is privately produced. The Pareto efficient allocation is for all players to co-operate in the production of such public good (full co-operation). Their model, however, allows a sub-set of players to co-operate (partial co-operation). The reduction of pollution is costly, so that every player has an incentive to free ride and thus to benefit from the reduction of pollution produced by other players.

They consider a situation in which there are $n$ regions. Each region produces pollution control, $z$, incurring a cost equal to $c(z)$, which is increasing and convex in $z$. At the same time, each region benefits from the aggregate value of pollution control produced in other countries. Let $Z$ be the aggregate level of pollution control. Then the payoff of each region is

$$
Z-c(z)
$$

In this setting, a coalition is an agreement to co-operate, so that the level of pollution control that maximises the coalition's aggregate payoff is chosen. In case of a coalition with $s$ members, the aggregate outcome for the coalition when each member produces $z$, is

$$
s\left(s z-c(z)+Z_{-i}\right)
$$

where $Z_{-i}$ is the pollution control produced by regions not in the coalition. In such a coalition, each member would produce a level of $z^{*}$ which solves

$$
\max _{z} s z-c(z)
$$

This means that, given that a coalition of size $s$ has formed, the amount of pollution control produced does not depend on the amount of pollution control produced by countries outside the coalition. In the jargon of game theory, the members have a dominant strategy in producing $z^{*}$ (this is because the externality is linear). 
For instance, if we assume that countries are similar, the decision to form a coalition (i.e., to reach an agreement) does not depend on the identity of the players, but just on their number. Let us further assume that the cost function is $c(z)=\frac{1}{2} z^{2}$, then the solution to equation (2) is $z=s$, which implies an aggregate production of pollution control for the coalition $s^{2}$. Therefore if there were $m$ coalitions with sizes $s_{j}$, with $j=1, \ldots, m$, then a coalition of size $s_{i}$ would get a per member payoff of

$$
\sum_{j=1}^{m} s_{j}^{2}-\frac{1}{2} s_{i}^{2}
$$

Note that in this exercise a coalition of size $s=1$ is a country which does not co-operate and decides to produce an amount of pollution control equal to 1 , which is the level that equate its private benefit and costs (from equation 2).

Ray and Vohra (2001) show that the possibility to obtain full co-operation rests on the number of players involved in the strategic game (in fact, this is the only parameter in the model, as countries are identical). There are many situations in which partial agreements are the equilibrium of the game so that the outcome is not Pareto efficient. The exercise also shows that the inefficient outcome emerges when a partial coalition forms.

\section{Example 2: International co-operation}

Feldstein (2013) discusses the current state of the European Union, pointing out that countries do not co-ordinate their policies. He considers the case of fiscal consolidation in Italy, Spain, Greece, and Portugal, where policies have been devised and implemented unilaterally rather than in a co-ordinated fashion. In the author's words: "the only exception is co-ordination of trade policies, where there are clear gains and where the required action can be stated as Thou shall not" (Feldstein, 2013, p. 9). In the view of the present work, the assertion of Feldstein is incomplete. As shown in the previous sections, the fact that everybody has a "clear" gain from the agreement is not sufficient to reach or sustain the co-operative strategy. In fact, in the prisoner's dilemma case, the players face both an incentive to free ride and a strategic risk, which lead them to adopt the non-co-operative strategy, though they can achieve a higher payoff by co-operating.

Unlike the EU trade agreement, the Doha Development Agenda (DDA) has reached an impasse and the prospect of future negotiations looks particularly grim. The DDA is a global trade negotiation, which started in 2001, with the aim of reaching a comprehensive agreement on the rules governing trade worldwide. Although the countries have "clear" gains from the global agreement, more than 10 years of negotiation have not led to any agreement. Perhaps the biggest difference with the EU trade agreement is the much larger number of countries involved in the DDA. This implies a greater heterogeneity in countries' characteristics and objectives. In fact, two main blocks confront each other, the developed countries (EU and USA) on one side, and the developing countries on the other side.

The different outcome of the two negotiations depends (in part) on the different way in which countries deals with the incentive to free ride and, to a smaller extent, the strategic risk. The EU represents an institution that can credibly enforce the deal, as the commission can punish (usually with sanctions) countries that do not abide to the agreement, thus reducing the free rider incentive. ${ }^{13}$ By contrast, the Doha

13. The credibility of EU institutions depends on the type of policy considered. The enforcement of the competition law is perhaps more credible than the enforcement of the growth and stability pact, because of the different players involved. In the former case, there is an involvement of private parties that are directly 
negotiations lack of a credible enforcement institution. The WTO Dispute Settlement in Geneva is not really an enforcement body.

Another interesting aspect of the DDA is that, regional and bilateral negotiations have proliferated as a consequence of the inability to reach a global agreement. According to our analysis on coalition formation, it might be that the possibility to reach an agreement with a subset of players (regional or bilateral trade agreements) is the cause of the failure to reach a global agreement. This would be the case if the benefits from free riding are higher than the benefits from reaching the agreement. This assessment would deserve a more detailed investigation, which is not carried out in the present work. The example has pointed out possible applications for the analysis conducted in the previous sections.

\section{Hints for field implementation}

The method described in the previous sections should serve as a guideline to better understand the problems of co-ordination that agents face in practice. To this end, it is important to define the cases in which it can be applied and what results can be reached with it.

The analyst should try to define the elements of the game that characterise the strategic interaction:

- the identity of the players involved, the actions they can take, and the order of moves (who can do what and when);

- the players' payoff in the status quo (this could be an approximation of the non-co-operative outcome);

- the incentive to free ride, as the difference between the payoff in case of co-operation and in case of deviation;

- the strategic risk, as the difference between the status quo and the payoff in case of being let down in the co-operative strategy.

Most of the information on the characteristics of the players depends on the institutional structure under which players interact. If they are members of the same organisation, for instance, their action space is determined by their role in the organisation; if they are public officials their actions and payoffs would depend on the government structure. Moreover, the incentive to deviate depends on the complementarity of actions and the possibility for a subset of players to produce something.

As regards the payoffs, the analysis would look at the present situation, with the associated payoffs for each player. If they are not co-operating, then the observed payoff is the status quo payoff. The payoffs from the other possible outcomes of the game are only potential payoffs. There might be a degree of uncertainty about their realisation. For the analysis, however, it is important to understand what is the payoff expected by each agent, as this would create the incentive to act, rather than trying to forecast the correct value. It is, then, important to understand how much of this information is shared amongst the players. In a complete information setting, each player should know the value other players expect from each outcome.

damaged by a breach in the competition law, while in the latter case the process is likely to involve a political negotiation between the EU member countries. 


\section{Concluding remarks}

The main goal of the work is to shed some light on the way in which co-operation (or the absence of co-operation) works. The analysis deliberately focuses on the cases in which the parties are aware that co-ordination would lead to a better result, but still they do not co-operate. This is because there are two obstacles to achieving co-ordination: the incentive to free-ride and the strategic risk.

The former represents the incentive to hold back and exploit the co-operative work of other agents, thus providing an incentive not to co-operate or to deviate from the co-operation strategy once the other agents are co-operating. The latter incentive represents the risk of losing resources if the other agents do not follow the same co-operative strategy. In many situations both incentives are presents, but it is possible to distinguish the situations where one of the incentives is predominant.

The main message is that both bottlenecks should be dealt with in order to achieve an efficient allocation of resources. What is good to remove the strategic risk maybe ineffective to tackle free-riding incentives, and vice versa. Therefore, it is important to identify the type of co-ordination failure that the parties may encounter, in order to devise the right instrument. This is relevant regardless of the source of the mechanism, external or internal.

The analysis has focused on a particular situation, where players know that there are gains from co-operation but still they might not co-operate. In reality, there are many situations where player do not know that there are gains from co-operation, or they do not know how to co-operate. Solving those information problems, however, is not sufficient to induce co-operation because player may face a free rider incentive or a strategic risk, or both. 


\section{BIBLIOGRAPHY}

Ahn, T. K., E. Ostrom, D. Schmidt, R. Shupp, and J. Walker (2001), "Cooperation in PD Games: Fear, Greed, and History Play", Public Choice, 106, 137-155.

Axelrod, R. (1984), The Evolution of Cooperation, New York: Basic Books.

Bartolini, D and A. Zazzaro (2011), The Impact of Antitrust Fines on the Formation of Collusive Cartels", B.E. Journal of Economic Analysis and Policy, 11(1).

Baumol, W. J. and W. E. Oates (1988), The Theory of Environmental Policy (2 ${ }^{\text {nd }}$ ed.), Cambridge University Press, New York.

Bolton, P. and M. Dewatripont (2005), Contract Theory. The MIT Press.

Bowles, S. (2004), Microeconomics: Behavior, Institutions, and Evolution, The Roundtable series in Behavioral Economics, Princeton University Press, New York.

Charron, N., Lapuente V., and L. Dykstra (forthcoming), "Regional Governance Matters: A Study on Regional Variation in Quality of Government within the EU, Regional Studies.

Coase, R. (1960), “The Problem of Social Costs”, Journal of Law and Economics, 3(1), 1-44.

David, P. (1985), "Clio and the Economics of QWERTY, American Economic Review, 75, 332-337.

Feldstein, M. (2013), Coordination in the European Union, NBER Working Paper No. 18672.

Farrel, J. and G. Saloner (1988), "Coordination through Committees and Markets", RAND Journal of Economics 19(2), 235-252.

Gibbons, R. (1992), A Primer in Game Theory, Pearson Education.

Hart, O. and J. Moore (1999), "Foundations of Incomplete Contracts", Review of Economic Studies, 66(1), $115-138$.

Hart, O. and J. Moore (2008), "Contracts as Reference Points", Quarterly Journal of Economics 123(1), $1-48$.

Howitt, P. (2001), “Coordination Failures”, Working Paper Brown University.

Kydland, F. and E. Prescott (1977), "Rules rather than Discretion: The Inconsistency of Optimal Plans", Journal of Political Economy, Vol. 85(3), p. 473-91.

Kreps, D. M. (1990). Game Theory and Economic Modelling, Claredon Lectures in Economics, Oxford University Press, New York. 
Murphy, K., A. Shleifer, and R. Vishny (1989), "Industrialization and the Big Push", Journal of Political Economy, 97(5), 1003-26.

Mas-Colell, A., M. D. Whiston, and J. R. Green (1995), Microeconomic Theory, Oxford University Press.

Nash, J. (1950). "Equilibrium Points in N-person Games", Proceedings of the National Academy of Sciences of the United States of America, 36(1), 48-49.

OECD (2007), Linking Regions and Central Governments: Contracts for Regional Development, OECD Publishing, doi: 10.1787/9789264008755-en.

OECD (2011), Making the Most of Public Investment in a Tight Fiscal Environment: Multi-level Governance Lessons from the Crisis, OECD Publishing, doi: 10.1787/9789264114470-en.

OECD (forthcoming), Rural-Urban Partnerships: An Integrated Approach to Economic Development, OECD Publishing, Paris.

Osborne, M. J. (2004), An introduction to Game Theory, Oxford University Press, New York.

Ostrom, E. (1990), Governing the Commons, Cambridge University Press, New York.

Pigou, A. C. (1932), The Economics of Welfare, MacMillan and Co, London.

Putnam, R. (1993), Making Democracy Work, Princeton University Press.

Rapaport, A. (1967), “A Note on the "Index of Cooperation” for Prisoner's Dilemma”, Journal of Conflict Resolution 11, 101-103.

Ray, D. (2007), A Game-Theoretic Perspective on Coalition Formation, Oxford University Press, Oxford.

Ray, D. and R. Vohra (2001), "Coalitional Power and Public Goods", Journal of Political Economy 109(6), 1355 - 1384.

Schelling, T. (1960), The Strategy of Conflict, Harvard University Press.

Weber, R. A. (2008), "Organizational Coordination: a Game-Theoretic View", Paper 5, Department of Social and Decision Theory. 